\title{
Expression of Nrf2 Promotes Schwann Cell-Mediated Sciatic Nerve Recovery in Diabetic Peripheral Neuropathy
}

\author{
Wei Tang Xiangfang Chen Haoqi Liu Qian Lv Junjie Zou Yongquan Shi \\ Zhimin Liu
}

Department of Endocrinology, Changzheng Hospital, Shanghai, China

Key Words

Hyperglycemia • Neuropathy • Sciatic vasa nervorum • Cell transplant • Angiogenesis.

\begin{abstract}
Background/Aims: High glucose-induced oxidative stress and inflammatory responses play an important role in painful diabetic neuropathy by activating the TLR4/NFKB signal pathway. Schwann cells (SCS) are integral to peripheral nerve biology, contributing to saltatory conduction along axons, nerve and axon development, and axonal regeneration. SCs provide a microenvironment favoring vascular regeneration but their low survival ratio in hyperglycemic conditions suppress the function to promote nerve growth. Nuclear factor erythroid 2-related factor 2 (Nrf2) promotes remyelination after peripheral nerve injury. The aim of this study was to identify the role of $\mathrm{Nrf2}$ in SC-mediated functional recovery after sciatic nerve injury. Methods: We compared plasma inflammatory factors in diabetic patients (DN) with/without diabetic peripheral neuropathy (DPN) and assessed whether Nrf2 expression in SCs could repair peripheral nerve injury in a rat model. Nrf2, TLR4/NFKB signal pathway and apoptosis relative protein expression were detected by western blot. Apoptosis and angiogenesis were determined by immunofluorescence and tubule formation assay, respectively. Regenerated nerves were determined by transmission electron microscope. Results: Higher levels of inflammatory factors and VEGF expression were found in DPN patients. Cellular experiments indicate that Nrf2 expression inhibits hyperglycemia-induced apoptosis and promotes angiogenesis by regulating the TLR4/NFKB signal pathway. Animal experiments show that nerve conduction velocity, myelin sheath thickness, and sciatic vasa nervorum are restored with transplantation of SCs overexpressing Nrf2. Conclusions: Taken together, the high survival ratio of SCs in a DPN rat model indicates that overexpression of Nrf2 restores nerve injury.
\end{abstract}

\section{Introduction}

Diabetes continues to be a serious health condition with the capacity to damage several tissues and organs including nerves and blood vessels. Complications resulting from these factors can give rise to debilitating peripheral neuropathy, approximately $50 \%$ of patients W. Tang and X. Chen contributed equally to this work.

\begin{tabular}{ll}
\hline Yongquan Shi & Department of Endocrinology, Shanghai Changzheng Hospital, \\
and Zhimin Liu & 415 Fengyang Road, Shanghai (China) \\
& E-Mail young.stone@163.com, zmliu_yzhao@hotmail.com
\end{tabular}




\section{Cellular Physiology Cell Physiol Biochem 2018;46:1879-1894 and Biochemistry Published online: Thay 02, $2018 \quad \begin{aligned} & \text { O 2018 The Author } \\ & \text { www.karger.com/cpb }\end{aligned}$}

Tang et al.: Nrf2 Overexpression in Schwann Cells

develop this condition during the progression of the disease $[1,2]$. The gradual deterioration of nerve function is characterized by slowing of nerve conduction velocity, abnormal thermal perception, axonal degeneration, paranodal demyelination and loss of myelinated fibers [3]. Diabetic peripheral neuropathy (DPN) is a major cause of morbidity that can lead to excessive foot ulceration and subsequent limb amputation [4]. The vascular mechanism of the neuropathy involves impaired endoneurial blood flow to peripheral nerves leading to the destruction of neuronal and Schwann cells (SCs) [5]. The pathogenesis of DPN is considered to be multifactorial. A combination of chronic hyperglycemia, oxidative stress, inflammation, microangiopathy of nerve blood vessels and a reduction in nerve fiber repair result in damage to the vasa nervorum, the microvessels that supply blood to neural tissue [6, 7]. High glucose can induce oxidative stress and inflammatory responses to activate the Toll-like receptor 4 (TLR4)/nuclear factor- $\kappa \mathrm{B}$ (NF- $\kappa \mathrm{B})$ signal pathway, which is believed to play an important role in DPN [8]. Although glycemic control can prevent the progression of DPN, whether it has the capability of reversing the condition has not been established.

Cell transplantation has proven to be a useful therapy for treating peripheral nerve injuries [9]. SCs are a type of glia cell that are involved in the maintenance and protection of myelinated and unmyelinated peripheral nerve fibers. They contribute to saltatory conduction along axons, nerve and axon development, and axonal regeneration. SCs also promote vascular regeneration owing to the production of several pro-angiogenic factors. However, hyperglycemic conditions reduce the survival ratio of SCs and consequently suppress their function in promoting nerve growth. Transplantation of SCs into bioengineered conduits can improve regeneration by bridging nerve grafts $[10,11]$. Previous studies have shown that adipose-derived stem cells (ASCs) can differentiate into neuron-like cells and SC-like cells in vitro [12]. Dai et al. tested the efficacy of different types of allogeneic cells including SCs, ASCs, dental pulp stem cells (DPSCs), and the combination of SCs with ASCs or DPSCs seeded on nerve conduits to repair rat sciatic nerves [13]. A combination of SCs and ASCs or DPCs resulted in the greatest functional recovery, as evaluated by walking track, functional gait, nerve conduction velocity, and histological analysis. The regenerative capacity of nerve grafts could possibly be further improved by genetically modifying SCs $[14,15]$.

Nuclear factor erythroid 2-related factor 2 (Nrf2) and NF-kB are two redox-regulated transcription factors involved in oxidative stress, inflammation, cellular growth, and apoptosis. Nrf2 is known to promote remyelination after peripheral nerve injury [16]. Recent studies support a defensive role of Nrf2 in neurons under conditions of oxidative stress and suggest that enhanced activation of Nrf2 inhibits the TLR4/NF- $\mathrm{KB}$ pathway and targets hemeoxygenase- 1 and NAD(P)H: quinone oxidoreductase 1 in neuro 2 a cells and the sciatic nerve of diabetic animals [17].

To further investigate the role of Nrf2 in SC-mediated functional recovery after sciatic nerve injury, we first compared plasma inflammatory factors of diabetic patients (DN) with and without DPN. We also studied the effects of high glucose on the expression and level of inflammatory factors in cultures of rat SCs and the role this played in SC survival with and without the overexpression of Nrf2. Then we determined the effect of Nrf2 overexpression in SCs on VEGF secretion and endothelial progenitor cell (EPC) migration. Lastly, we assessed the therapeutic efficacy of Nrf2 overexpression in SCs through targeted muscular injection in a diabetic rat model with peripheral nerve injury.

\section{Materials and Methods}

\section{Ethics Statement}

All animal/human experiments were performed with the approval of the animal/human ethics committee of the Shanghai Changzheng Hospital, China. Experiments were conducted by following established guidelines for animal/human care and were approved by the animal/human ethics committee of the Shanghai Changzheng Hospital, China. 


\section{Cellular Physiology Cell Physiol Biochem 2018;46:1879-1894

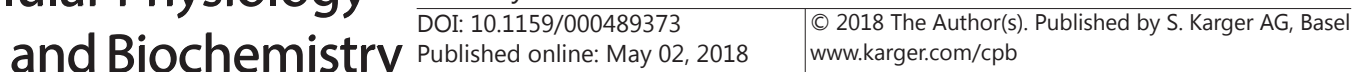

Tang et al.: Nrf2 Overexpression in Schwann Cells

\section{Reagents}

Antibodies against GAPDH, p-VEGFR2, VEGFR2, VEGF, TLR4, NFKB, Nrf2, MyD88, cleaved caspase-3, B-cell lymphoma 2 (Bcl-2), Bax, NOX1, NOX4, IL-1 $\beta$, IL-6 and tumor necrosis factor- $\alpha$ (TNF- $\alpha$ ) were purchased from Sigma-Aldrich (St Louis, MO, USA). Streptozotocin (STZ), TAK-242 and YC-1 were purchased from Abcam (Cambridge, MA, USA). Dulbecco's modified Eagle's medium (DMEM, high glucose, HG) and fetal bovine serum were from Nego (Shanghai, China). Cell lysis buffer $(10 \times)$ was from Cell Signaling Technology (Beverly, MA, USA), DAPI was from Roche (Mannheim, Germany) and trypsin was obtained from SigmaAldrich. All other chemicals and reagents were of analytical grade.

\section{Subjects}

A total of 104 subjects were recruited from Shanghai Changzheng Hospital from April 2014 to June 2015. The normal control subjects (NC, $n=25$ ) had no family history of diabetes or other chronic diseases, normal glucose tolerance, were free of any major organ disease, and had a stable body weight for at least one year. The diagnosis of type 2 diabetes mellitus (T2DM, $n=79$ ) was performed according to the criteria of the American Diabetes Association (2012). In brief, patients with a whole blood glycated hemoglobin (HbA1c) $\geq 6.5 \%$, fasting plasma glucose level $\geq 126 \mathrm{mg} / \mathrm{dl}$ or 2 -h plasma glucose $\geq 200 \mathrm{mg} /$ $\mathrm{dl}$ during an oral glucose-tolerance test at diagnosis and who had received stable antidiabetic treatment for a minimum of 6 months were diagnosed with diabetes. The inclusion criteria for the patients studied were the following: (1) diabetes duration $>6$ months, (2) age was $>40$ and less than 70 years and (3) both sexes were involved. Exclusion criteria were as follows: patients with renal dysfunction, liver disease, angina pectoris, hypertrophic cardiomyopathy, history of myocardial infarction, heart failure, hypertension, stroke, peripheral vascular diseases, pregnancy, history of alcohol abuse, smoking, psychotropic drugs, diabetic retinopathy, nephropathy or microalbuminuria and any other conditions related to neuropathy. The study was approved by the ethical committee at Shanghai Changzheng Hospital, China. A written, signed and informed consent was obtained from each participant. Diabetic patients were divided into two groups according to the presence or absence of peripheral neuropathy: 39 diabetic patients without peripheral neuropathy (Group I, Non-DPN) and 40 diabetic patients with DPN (Group II). None of the controls had a history of hyperglycemia, evidence of neuropathy or renal disease.

A detailed questionnaire was completed for each of the 104 participants. The obtained information included age, sex, duration of T2DM, body mass index (BMI, weight in kilogram/squared height in meters) and diastolic blood pressure.

\section{Biochemical Assessments}

Fasting (12 h) blood samples were collected for laboratory analysis on the same day as the subjects' examination. Ten milliliters of blood were collected into a tube containing ethylenediaminetetraacetic acid, and $20 \mu \mathrm{l}$ was used for the determination of $\mathrm{HbA1c}$ by ion exchange high-performance liquid chromatography using the BioRad D-10 (France) hemoglobin testing system. The remaining blood was immediately centrifuged under refrigeration at $3000 \mathrm{rpm}$ for $10 \mathrm{~min}$ for the separation of plasma. The plasma was used to estimate fasting plasma glucose, total cholesterol, and triglycerides using commercial kits supplied by Stanbio (TX, USA). Plasma C-reactive protein (CRP), was measured by ELISA using a kit manufactured by Dia MedEuro Gen (Turnhout, Belgium), with a minimal detectable concentration of approximately $0.02 \mathrm{mg} /$ $\mathrm{dl}$ (intra-assay coefficient of variations (CVs) were 4.1-6.9\% and inter-assay CVs were 5.8-6.3\%.). Plasma VEGF, IL-1 $\beta$, IL-6, and TNF- $\alpha$ were measured by an ELISA kit manufactured by Orgenium Laboratories (Helsinki, Finland), with a minimal detectable concentration of approximately $5 \mathrm{pg} / \mathrm{ml}$ (assay range: 15.62$1000 \mathrm{pg} / \mathrm{ml}$; intra-assay CVs were < 6\% and inter-assay were CVs <10\%). Plasma TLR4 was measured by an ELISA kit manufactured by EIAB (China), with a minimal detectable concentration of approximately 0.39 $\mathrm{ng} / \mathrm{ml}$ (assay range: $0.48-50 \mathrm{ng} / \mathrm{ml}$; intra-assay CVs were $<3.0 \%$ and inter-assay CVs were $<6.3 \%$ ).

\section{Schwann Cell Culture}

Rat SCs derived from a culture of rat primary cells (ATCC: CRL-2765, Manassas, VA, USA) were purchased and cultured in T75 flasks with DMEM (containing $4 \mathrm{mM}$ l-glutamine, $1.5 \mathrm{~g} / \mathrm{L}$ sodium bicarbonate, and $5.5 \mathrm{mM}$ glucose; Gibco), supplemented with $100 \mathrm{U} / \mathrm{ml}$ penicillin, $100 \mathrm{mg} / \mathrm{ml}$ streptomycin, and $10 \%$ fetal bovine serum in an incubator. The culture medium was refreshed every 2 days. Cells from the 2 nd to 5 th passages were used in this study. 


\section{Cellular Physiology Cell Physiol Biochem 2018;46:1879-1894 \begin{tabular}{l|l} 
and Biochemistry Published online: May 02, 2018 & $\begin{array}{l}\text { () 2018 The Author(s). Published by S. Karger AG, Basel } \\
\text { www.karger.com/cpb }\end{array}$ \\
\cline { 2 - 3 } & DOI 10.159/00049373
\end{tabular}}

Tang et al.: Nrf2 Overexpression in Schwann Cells

To analyze the effect of TLR4 on HG-induced cellular damage. SCs were cultured for $48 \mathrm{~h}$ under normal glucose (NG) or HG conditions with or without $10 \mathrm{nM}$ TAK-242 (TLR4 inhibitor) treatment and then collected for further analysis.

\section{Induction of Diabetes}

Seven to eight-week-old male Sprague Dawley (SD) rats weighing 200-250 g were provided by Shanghai SLAC Laboratory Animal Co., Ltd. (China) and housed in individual microisolators or cages with free access to sterile acidified water and irradiated food in a specific pathogen-free facility. Diabetes was induced in the rats by intraperitoneal injections of STZ at a dose of $55 \mathrm{mg} / \mathrm{kg}$ in sodium citrate buffer (pH 4.5) for 5 consecutive days at 7 to 8 weeks of age [9]. Control rats were treated with daily injections of citrate buffer. One week after the last injection, serum glucose was measured from the tail vein by using a glucometer. Rats with plasma glucose concentrations of $250 \mathrm{mg} / \mathrm{dl}$ were selected as the STZ-induced diabetic group. Rats were housed in a room maintained under controlled temperature and humidity on a 12 h/12 h light/dark cycle.

\section{Surgical and Transplantation Procedure}

Rats were anesthetized with an isoflurane gas anesthesia system and kept in a constant flow of isoflurane inhalation. The skin in the upper left leg was shaved and prepared with $10 \%$ betadine solution. An incision was made on the mid-thigh muscle of the hind left leg to expose the sciatic nerve. The sciatic nerve was carefully lifted and crushed using a No. 5 Jeweler's forceps for a period of $30 \mathrm{~s}$, stopped for a $10 \mathrm{~s}$ interval and then crushed at the same site again for a $30 \mathrm{~s}$ period. For the sham, the nerve was exposed but not crushed. The incision in the muscle was closed with a 5-0 vicryl suture followed by closure of the skin with 5-0 silk. The right contralateral nerve served as a control.

One week after neurography, SCs used for qualitative (immunohistochemical) studies were labeled with GFP (BrdU, Abcam, UK) $48 \mathrm{~h}$ prior to transplantation. Approximately, $1 \times 10^{6} \mathrm{SCs}$ in $1 \mathrm{ml}$ total fluid volume of PBS were prepared for the study. The diabetic rats were randomly divided into three groups: Control (1 ml PBS), SCs, and Nrf2-SCs. Suspensions were injected into the medial and lateral heads of the gastrocnemius muscle. Each group contained six rats.

\section{Lentiviral Vector Construction and Infection}

Rat Nrf2 full-length cDNA was generated by polymerase chain reaction (PCR) using forward primer: 5'-GAACCGGTATGATGGACTTGGAGTTGC-3', and reverse primer: 5'-CGGCGAGACTAGTTTTTTCTTTGTATC-3' . The amplified fragment was then subcloned into plasmid pGC-FU-EGFP-3FLAG (GeneChem, Shanghai, China) after AgeI/NheI restriction enzyme digestion to produce pGC-FU-Nrf2-3FLAG. To generate lentiviral particles, H9c2 cells were co-transfected with $20 \mu \mathrm{g}$ of NEDD4-1 or their specific control vector, with pHelper $1.0(15 \mu \mathrm{g})$ and pHelper 2.0 lentiviral packing plasmid $(10 \mu \mathrm{g})$ (GeneChem) into $293 \mathrm{~T}$ packaging cells using Lipofectamine 2000 (Invitrogen, Carlsbad, CA, USA). After 48 h, the lentivirus-containing supernatants were harvested and used for the infection of SCs.

\section{Quantitative Real-Time PCR}

Total RNA was extracted and purified using Trizol reagent (Invitrogen) following manufacturer's instructions. Quantitative real-time PCR was performed on prepared cDNA using SYBR Green Realtime PCR Master Mix (Applied Biosystems, Foster City, CA, USA) on an ABI Step One Plus real-time PCR system. The specific primers used in the PCR were as follows: GAPDH, 5'-ATGGGGAAGGTGAAGGTCG-3' (sense) and 5'-GGGGTCATTGATGGCAACAATA-3' (antisense); VEGF, 5'-TGAGACCCTGGTGGACA-3' (sense)

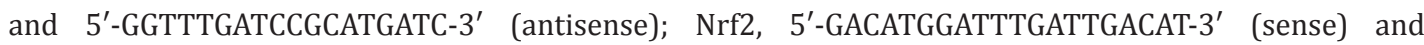
5'-CCTTCTCCTGTTCCTTCTGG-3' (antisense). NADPH oxidase 1, 5' -ACTGGCTGGTTAACCAC-3' (sense) and $5^{\prime}$-CTCTCGTGTAATAGTA-3' (antisense). NADPH oxidase 4, 5' -CTGGAAAACCTTCCTGC-3' (sense) and $5^{\prime}$-GGCTGCAGTTGAGGTTC-3' (antisense). The cycle threshold (Ct) values were standardized to Ct values of GAPDH. Fold difference in occupancy was calculated as Fold difference $=2^{-\Delta \Delta c t}$.

Detection of Intracellular ROS

Intracellular reactive oxygen species (ROS) were determined by laser scanning confocal microscopic analysis with a peroxide-sensitive fluorescent probe DCFH2DA and DHE, respectively. DCFH2DA is mainly 


\section{Cellular Physiology Cell Physiol Biochem 2018;46:1879-1894 \begin{tabular}{l|l|l}
\cline { 2 - 3 } DOI: 10.1159/000489373 & (c) 2018 The Author(s). Published by S. Karger AG, Basel
\end{tabular} and Biochemistry Published online: May 02, 2018 www.karger.com/cpb}

Tang et al.: Nrf2 Overexpression in Schwann Cells

oxidized by hydrogen peroxides, while DHE is mainly oxidized by superoxide anions. DCFH2DA and DHE were the practice probes used to detect cellular ROS levels in viable cells. In brief, cells at $1 \times 10^{5} / \mathrm{ml}$ in different culture conditions were harvested and treated with $10 \mathrm{mM}$ of DCFH2DA or $10 \mathrm{mM}$ of DHE at $37{ }^{\circ} \mathrm{C}$ for $30 \mathrm{~min}$ in the dark. After being washed twice with PBS, the fluorescent intensity of the different groups of cells was analyzed by FV1000 (excitation $488 \mathrm{~nm}$ for DHE and DCFH2DA).

\section{Determination of Apoptotic Cells}

Primary SCs cells were seeded onto 6-well plates at a density of $1 \times 10^{6}$ cells /well. The cells were starved overnight and treated in triplicate with different concentrations of glucose (NG, $5.5 \mathrm{mM}$ and HG, $30 \mathrm{mM}$ )). The cells were digested with trypsin, centrifuged and washed twice with PBS. They were then incubated in annexin V-PE/7-AAD for 15 min in the dark. Stained cells were analyzed using BD FACS Canto II (BD Biosciences, San Jose, CA, USA). Results from 100, 00 events were analyzed in each sample and corrected for autofluorescence with unlabeled cells.

\section{Western Blot Analysis}

The protein samples from primary SCs cells or tissue around sciatic nerve were lysed with buffer containing $1 \% \mathrm{NP}-40,0.5 \%$ sodium deoxycholate, $0.1 \%$ sodium dodecyl sulfate (SDS), and a protease inhibitor mixture (phenylmethylsulfonyl fluoride, aprotinin, and sodium orthovanadate) then subjected to sodium dodecyl sulfate-polyacrylamide gel electrophoresis and transferred to a polyvinylidene difluoride membrane. Membranes were blocked with TBST containing 5\% milk and incubated with different primary antibodies as indicated overnight at $4{ }^{\circ} \mathrm{C}$. The membranes were then incubated with horseradish peroxidase-conjugated secondary antibodies and visualized using an enhanced chemiluminescence system. Densitometric analysis was performed using Scion Image software (Scion, Frederick, MD, USA).

\section{Tube Formation Assay}

Cell co-culture was performed using a double-chamber co-culture system with a $0.4 \mu \mathrm{m}$ pore size membrane (12-well insert, BD Biosciences) separating the upper and lower chamber cells. SCs $\left(1 \times 10^{5}\right.$ cells/well) were cultured in the upper chamber and EPCs $\left(1 \times 10^{5}\right.$ cells/well $)$ were cultured in the lower chamber, followed by addition of GKT137831 (NOX1/4 inhibitor, $20 \mathrm{ng} / \mathrm{ml}$ ) or CBO-P11 (VEGF inhibitor, 10 $\mu \mathrm{M})(100 \mathrm{ng} / \mathrm{ml})$ for $48 \mathrm{~h}$ under HG conditions. The supernatants were then collected for VEGF assays. EPCs in the lower chamber were collected for VEGFR2 analysis.

\section{Fluorescent Imaging of Vasa Nervorum}

Vascularity of sciatic vasa nervorum was examined by in situ fluorescent staining by using NeuN and CD31 staining [9]. The sciatic nerves from anesthetized rats were removed, fixed overnight at $4{ }^{\circ} \mathrm{C}$, incubated in $30 \%$ sucrose at $4{ }^{\circ} \mathrm{C}$ until equilibrated and embedded in OCT compound for frozen sectioning. Sequential $8 \mu \mathrm{m}$ thick cross-sections were cut on a cryostat (CM3050S; Leica) and stored at $-20^{\circ} \mathrm{C}$. Fluorescence was then detected by using a confocal microscope (Olympus FV1000, Japan). Fluorescent-labeled sciatic vasa nervorum were counted per cross-section; typically, four different sections were counted and averaged.

\section{Sciatic Nerve Conduction Velocity}

The animals were anesthetized with $10 \%$ chloral hydrate $(10 \mathrm{ml} / \mathrm{kg})$. The stimulating and recording electrodes were placed directly under the sciatic nerve of the right leg. The skin was incised and detached between the biceps femoris and semitendinosus muscles to expose the sciatic nerve at two sites to attach electrodes. The stimulation electrode was placed at the sciatic nerve notch and the ankle. The sciatic nerve was stimulated with a single square wave pulse (1.2 V in intensity, $1 \mathrm{~ms}$ in width) using the Functional Experiment System (BL-420 s, Taimeng, Sichuan, China). The action potential latency (L) of the sciatic nerve and the distance (D) between the stimulating and recording electrodes were measured to calculate the motor nerve conduction velocity (MNCV (m/s) = D/L). For sciatic nerve conduction velocity (SNCV), the site of recording was located in the sciatic notch. SNCV was calculated in the same way as the MNCV.

\section{Transmission Electron Microscopy}

The sciatic nerve tissue was isolated as described before and placed in $2.5 \%$ glutaraldehyde. After the sample was cut into $1 \times 1 \times 3-4 \mathrm{~mm}$, the nerve was divided into four parts longitudinally and fixed in $2.5 \%$ 


\section{Cellular Physiology Cell Physiol Biochem 2018;46:1879-1894

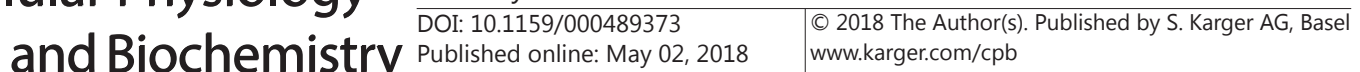

Tang et al.: Nrf2 Overexpression in Schwann Cells

glutaraldehyde at $4{ }^{\circ} \mathrm{C}$ overnight. The tissue was then post-fixated with $1 \%$ osmium tetroxide for 1 hour and embedded in Epon 812 resin. The tissue was cut into ultrathin sections $(60 \mathrm{~nm})$ and double stained with uranyl acetate and lead citrate for $10 \mathrm{~min}$. After dehydration with ethanol and acetone, respectively, the samples were examined under transmission electron microscopy (Hitachi, Japan) for ultra-structural analysis of myelin sheath formation. At 4 weeks, the thickness of the myelin sheath of new myelinated nerve fibers and the diameter of axons were detected in both groups.

\section{Statistical Analysis}

All data are presented as the mean \pm SD. Differences between treatment groups were analyzed using one-way ANOVA with post hoc tests (Tukey's multiple comparisons test) using GraphPad Prism 6.0 software. In all cases, $\mathrm{p}<0.05$ was considered to be statistically significant.

\section{Results}

\section{Inflammatory Factors and VEGF Expression are Higher in Patients with Diabetic Peripheral} Neuropathy

We carried out biochemical analyses to investigate the difference between inflammatory factors and VEGF expression in DN and DPN patients (Table 1). The inflammatory factor IL-6, VEGF expression, and triglycerides were highly significant in DPN patients compared with DN patients $(P<0.01)$. Levels of IL-1 $\beta$, TNF-a, and TLR4, were also higher in DPN patients compared with DN patients $(P<0.05)$. All the factors measured, including $\mathrm{HbA1c}$, fasting plasma glucose, IL-6, IL-1 $\beta$, VEGF, and TLR4, were higher in DN and DPN patients compared to patients in the control group (Table 1). These results confirm that inflammatory factors and VEGF expression are higher in patients with high plasma glucose levels and these levels increase with the progression of the disease and presence of peripheral neuropathy.

\section{High Glucose Increases ROS and Inflammatory Factor Levels Through the TLR4/NFKB Pathway in Schwann Cells \\ When SCs are cultured} with NG or HG with or

Table 1. Comparison between demographic and laboratory characteristics of diabetic patients with or without diabetic peripheral neuropathy and controls. Data are expressed as mean \pm SD. ${ }^{* *} \mathrm{p}<0.01$, ${ }^{* * *} \mathrm{p}<0.001$ against the control values. ${ }^{\dagger} \mathrm{p}<0.05,{ }^{+\dagger} \mathrm{p}<0.01,{ }^{+\dagger+} \mathrm{p}<0.001$ against the diabetes values. DPN, diabetic peripheral neuropathy; HbA1c, whole blood glycated hemoglobin; FPG, fasting plasma glucose; TC, total cholesterol; TG, triglycerides; DBP, diastolic blood pressure; CRP, plasma C-reactive protein; VEGF, vascular endothelial growth factor; TLR4, Toll-like receptor 4

\begin{tabular}{|c|c|c|c|}
\hline & & Diabetic & \\
\hline Clinical parameter & Control & $\begin{array}{l}\text { Group I } \\
\text { (without DPN) }\end{array}$ & $\begin{array}{l}\text { Group II } \\
\text { (with DPN) }\end{array}$ \\
\hline No. of patients & 25 & 39 & 40 \\
\hline Age (years) & $53.84 \pm 18.8$ & $57.74 \pm 13.32$ & $61.93 \pm 12.46$ \\
\hline Sex (male/female) & $11 / 14$ & $23 / 16$ & $25 / 15$ \\
\hline Body mass index $\left(\mathrm{kg} / \mathrm{m}^{2}\right)$ & $22.98 \pm 2.40$ & $25.88 \pm 4.55$ & $24.14 \pm 3.15$ \\
\hline Duration of diabetes (years) & 0 & $9.96 \pm 8.55$ & $13.21 \pm 8.0$ \\
\hline HbA1c (\%) & $5.4 \pm 0.53$ & $8.64 \pm 2.0^{* * *}$ & $8.97 \pm 2.0^{* * *}$ \\
\hline FPG (mg/dl) & $84 \pm 11.35$ & $153 \pm 15.37^{* * *}$ & $196 \pm 23.21^{* * *+}$ \\
\hline $\mathrm{TC}(\mathrm{mg} / \mathrm{dl})$ & $133 \pm 15.68$ & $182.67 \pm 21.38^{* *}$ & $215.22 \pm 18.59^{* * *+t}$ \\
\hline $\mathrm{TG}(\mathrm{mg} / \mathrm{dl})$ & $99.58 \pm 12.34$ & $158.25 \pm 17.82^{* *}$ & $208.32 \pm 21.36^{* * *+t}$ \\
\hline DBP (mmHg) & $116.32 \pm 14.0$ & $126.23 \pm 17.51$ & $130.75 \pm 20.56^{* *}$ \\
\hline CRP (mg/l) & $3.45 \pm 1.56$ & $4.02 \pm 2.38$ & $3.7 \pm 1.97$ \\
\hline VEGF (pg/ml) & $123.2 \pm 24.38$ & $316.88 \pm 26.33^{* * *}$ & $428.25 \pm 28.67^{* * *+++}$ \\
\hline TLR4 (pg/ml) & $584.64 \pm 64.04$ & $879.58 \pm 61.55^{* * *}$ & $1256.1 \pm 153.22^{* * *++\dagger}$ \\
\hline IL-6 (pg/ml) & $128 \pm 32.17$ & $580.03 \pm 48.02^{* * *}$ & $888.37 \pm 48.59^{* * *+1+}$ \\
\hline $\mathrm{IL}-1 \beta(\mathrm{pg} / \mathrm{ml})$ & $58.28 \pm 15.17$ & $215.95 \pm 349.61^{* * *}$ & $347.55 \pm 54.84^{* * *+++}$ \\
\hline TNF-a $(\mathrm{pg} / \mathrm{ml})$ & $70.88 \pm 17.28$ & $321.67 \pm 58.25^{* * *}$ & $579.58 \pm 43.56^{* * *++t}$ \\
\hline
\end{tabular}




\section{Cellular Physiology Cell Physiol Biochem 2018;46:1879-1894

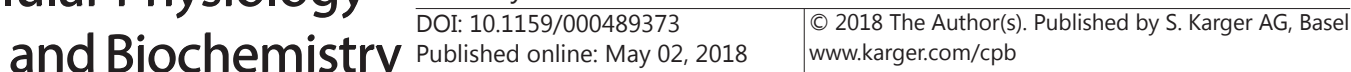 Tang et al.: Nrf2 Overexpression in Schwann Cells}

without TAK-242 and then observed through fluorescent imaging, peroxide and superoxide anion levels are found to be higher with HG but the strength of the fluorescence signal is reduced by the addition of the TLR4 inhibitor TAK242 (Fig. 1a). Peroxide and superoxide levels were significantly higher in SCs cultured with HG than with NG $(P<0.001)$ but this increase was less obvious when TLR4 is inhibited $(P<$ 0.05 ) and peroxide and superoxide levels were significantly lower than in SCs without TAK-242 even in HG $(P<0.01)$ (Fig. 1b). mRNA and protein levels of NADPH oxidase isoform 1 (NOX1) and 4 (NOX4) in RSC96 cells analyzed with qPCR and western blots gave a similar pattern of results (Fig. 1c). Inflammatory cytokine levels of IL-1 $1 \beta$, IL- 6 and TNF- $\alpha$ for both glucose concentrations were also measured (Fig. 1d) and again were found to be significantly higher in SCs cultured with HG compared with NG $(P<0.001)$. The presence of TAK242 reduced these levels significantly $(P<0.01$ vs HG, $P<0.05$ vs NG). Taken together, these results indicate that HG can induce ROS and inflammatory factor levels through the TLR4/NFKB pathway in SCs. Furthermore, when apoptosis was assessed using flow cytometry with annexin v-PE/7-AAD staining, it was found that high ROS and inflammatory factor levels affect the survival of SCs cultured in HG (Fig. 2a). Western blot analysis was used to confirm the role of TLR4/NFKB with or without TAK-242 under HG conditions (Fig. 2b). Levels of TLR4, MyD88, $\mathrm{NF} \kappa \mathrm{B}, \mathrm{Bax}$, and cleaved caspase-3 were all significantly higher in SCs cultured in $\mathrm{HG}$ than in NG $(P<0.001)$ whereas these levels were reduced when cells were cultured in the presence of TAK242 with levels of TLR4 $(P<0.001)$, MyD88 $(P<0.05)$, and NFKB $(P<$ $0.05)$ significantly lower than in SCs cultured in NG. In contrast, levels of the apoptosis-regulating protein $\mathrm{Bcl}-2$ were significantly reduced in response to $\mathrm{HG}(P<0.001)$ but levels increase in

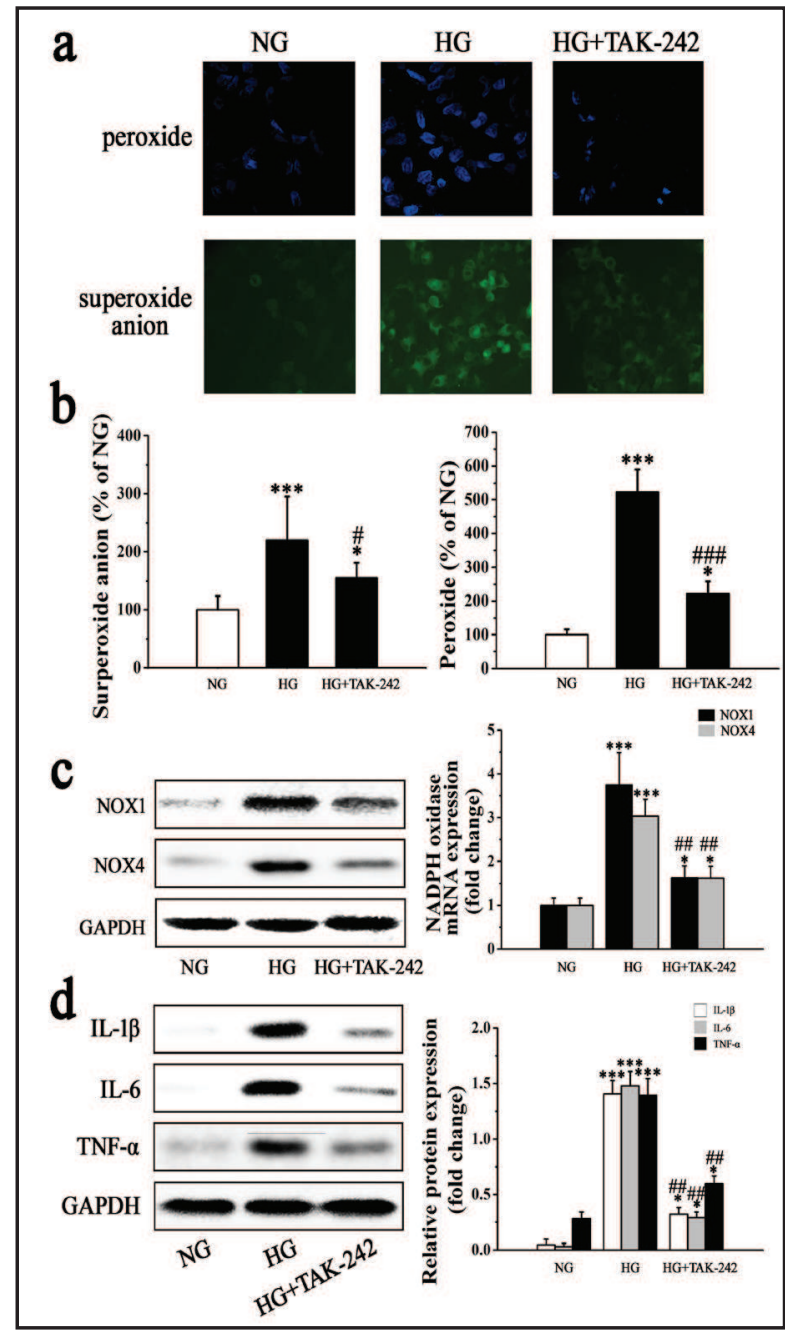

Fig. 1. High glucose (HG) induction promotes ROS and inflammatory factor levels through the TLR4/NFKB pathway in Schwann cells (SCs). SCs were cultured with $5.5 \mathrm{mM}$ or $30 \mathrm{mM}$ glucose for $48 \mathrm{~h}$ with or without a TLR4 inhibitor (TAK-242, $10 \mathrm{nM}$ ). (a) Effects of HG on peroxide and superoxide anion levels. SCs were stained with DCFH2DA and DHE, fluorescent markers for peroxide and superoxide anions, respectively. (b) Data analysis. Data were represented as the mean $\pm \mathrm{SD}(\mathrm{n}=5) .{ }^{*} \mathrm{P}<0.05$, ${ }^{* * *} \mathrm{P}<$ 0.001 vs normal glucose $(\mathrm{NG})$. ${ }^{\#} \mathrm{P}<0.05$, ${ }^{\# \# \#} \mathrm{P}<0.001$ vs $\mathrm{HG}$. The ratio is defined as a percentage of the NG group (being 100\%). (c) mRNA and protein levels of NADPH oxidase isoform 1 (NOX1) and 4 (NOX4) in RSC96 cells as represented by Rt-PCR and western blots, respectively. Data are represented as mean $\pm \mathrm{SD}(\mathrm{n}=5) .{ }^{*} \mathrm{P}<0.05$, ${ }^{* * *} \mathrm{P}<$ 0.001 vs NG. ${ }^{\# \#} \mathrm{P}<0.01$ vs HG. (d) Inflammatory cytokine levels of IL-1 $\beta$, IL-6, and TNF- $\alpha$ in each group. Data are represented as mean $\pm S D(n=5) .{ }^{*} \mathrm{P}<0.05$, ${ }^{* * *} \mathrm{P}<0.001$ vs $\mathrm{NG},{ }^{\# \#} \mathrm{P}<0.01$ vs HG. 


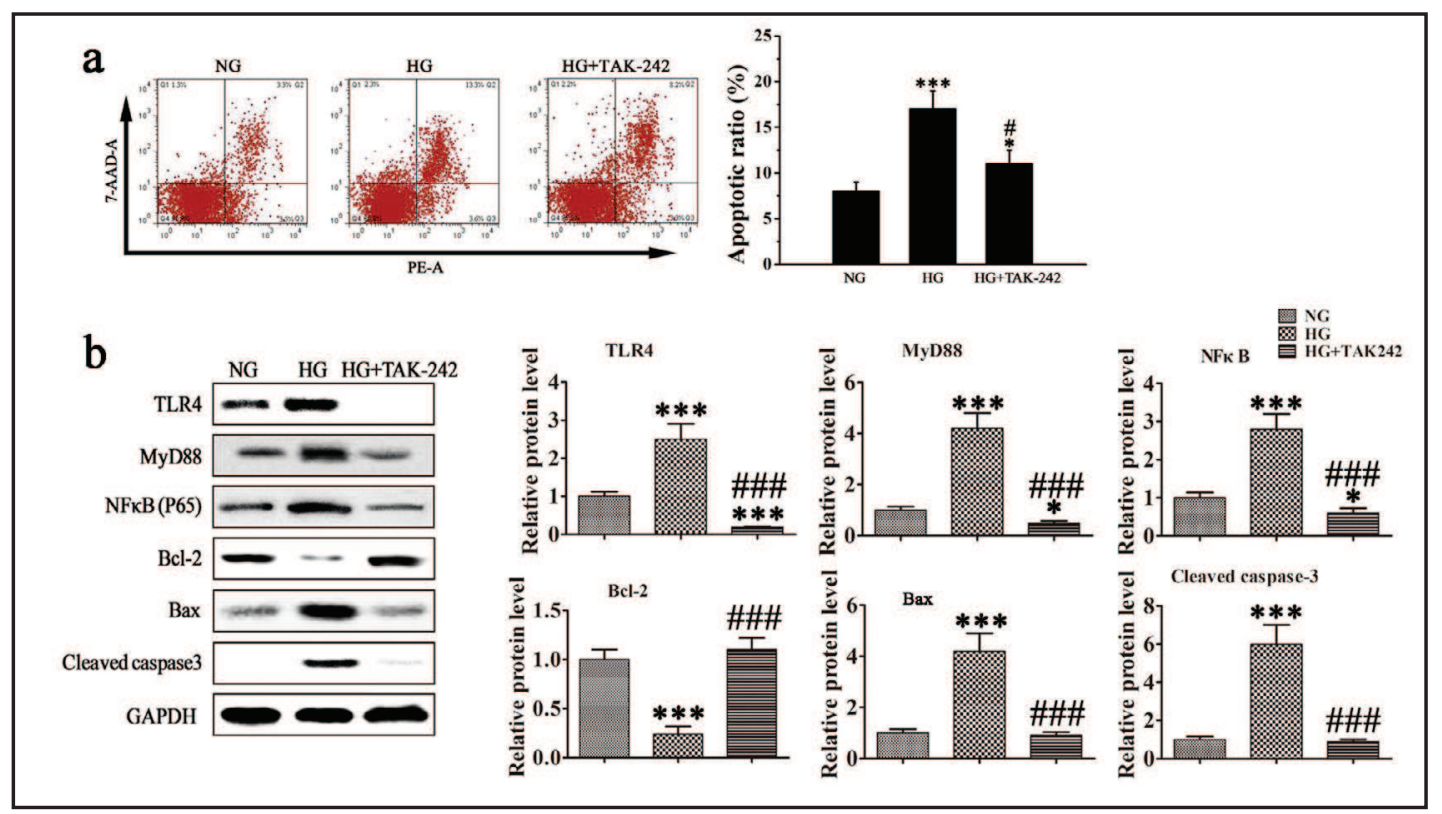

Fig. 2. The survival of Schwann cells (SCs) was inhibited with high ROS and inflammatory factors in high glucose (HG) conditions. (a) Effects of HG on SC apoptosis. SCs were treated with normal glucose (NM, $5.5 \mathrm{mM}), \mathrm{HG}(30 \mathrm{mM})$ and TAK-242 (10 $\mathrm{nM})$ for $48 \mathrm{~h}$. Apoptosis was assessed using flow cytometry with annexin $\mathrm{v}-\mathrm{PE} / 7-\mathrm{AAD}$ staining. The relative apoptotic ratio with at least five repeats. Data are represented as mean $\pm \mathrm{SD}(\mathrm{n}=5) .{ }^{*} \mathrm{P}<0.05,{ }^{* * *} \mathrm{P}<0.001$ vs $\mathrm{NG}$. ${ }^{*} \mathrm{P}<0.05$ vs HG. (b) Western blots were used to analyze the role of TLR4/NFKB with or without TAK-242 under HG conditions. The relative protein expression was measured in at least five repeats. Data are represented as mean $\pm \mathrm{SD}(\mathrm{n}=5) .{ }^{*} \mathrm{P}<0.05,{ }^{* * *} \mathrm{P}<0.001$ vs NG . \#\#\# $\mathrm{P} 0.001$ vs HG.

the presence of TAK-242 $(P<0.001 \mathrm{vs} \mathrm{HG})$. These findings support the theory that apoptosis increases in hyperglycemic conditions.

The Expression of Nrf2 Promotes the Survival of Schwann Cells in High Glucose by Inhibiting TLR4/NFKB-Mediated ROS and Inflammatory Responses

The relative protein and RNA levels of Nrf2 were measured by western blot and Rt-PCR, respectively. The levels of Nrf2 protein and RNA were upregulated after transfection with a Nrf2 expression vector $(P<0.001)$ (Fig. 3a). Apoptosis was assessed using flow cytometry with annexin v-PE/7-AAD staining (Fig. 3b). The number of SCs entering apoptosis in HG conditions decreased with overexpression of Nrf2 $(P<0.05$ vs NG, $P<0.001$ vs HG). To understand the influence of TLR4/NFkB signaling in apoptosis the relative protein levels of TLR4, NFKB, Bcl-2, Bax, and cleaved caspase- 3 were measured by western blotting in SCs overexpressing Nrf2 (Fig. 3c). As described above, levels of TLR4, NFKB, Bax, and cleaved caspase-3 increased in HG $(P<0.001)$ while Bcl-2 levels decreased $(P<0.001)$. In response to Nrf2 overexpression, levels of proteins associated with TLR4/NFKB signaling declined. Protein levels of TLR4 returned to those found in NG conditions $(P<0.001 \mathrm{vs} \mathrm{HG})$ while they were significantly decreased compared to HG levels of NFKB $(P<0.001$ vs $\mathrm{HG}, P<0.01$ vs NG), Bax $(P<0.001$ vs HG, $P<0.001$ vs NG), and cleaved caspase- $3(P<0.01$ vs $\mathrm{HG}, P<0.01$ vs NG) but still higher than those of NG levels. Protein levels of the apoptosis regulator Bcl-2 were reduced in HG $(P<0.001)$ but increased with Nrf2 overexpression $(P<0.05)$ although levels remained significantly lower than in SCs cultured in NG $(P<0.05)$. The expression of the ROS-related proteins NOX1 and NOX4 were also measured in SCs overexpressing Nrf2 by western blotting in HG conditions (Fig. 3d). Our results found that levels of NOX1 and NOX4 were significantly increased in SCs cultured in HG but when Nrf2 is overexpressed under these conditions levels of both NOX1 $(P<0.01$ vs HG, $P<0.01$ vs NG) and NOX4 $(P<0.05$ vs 


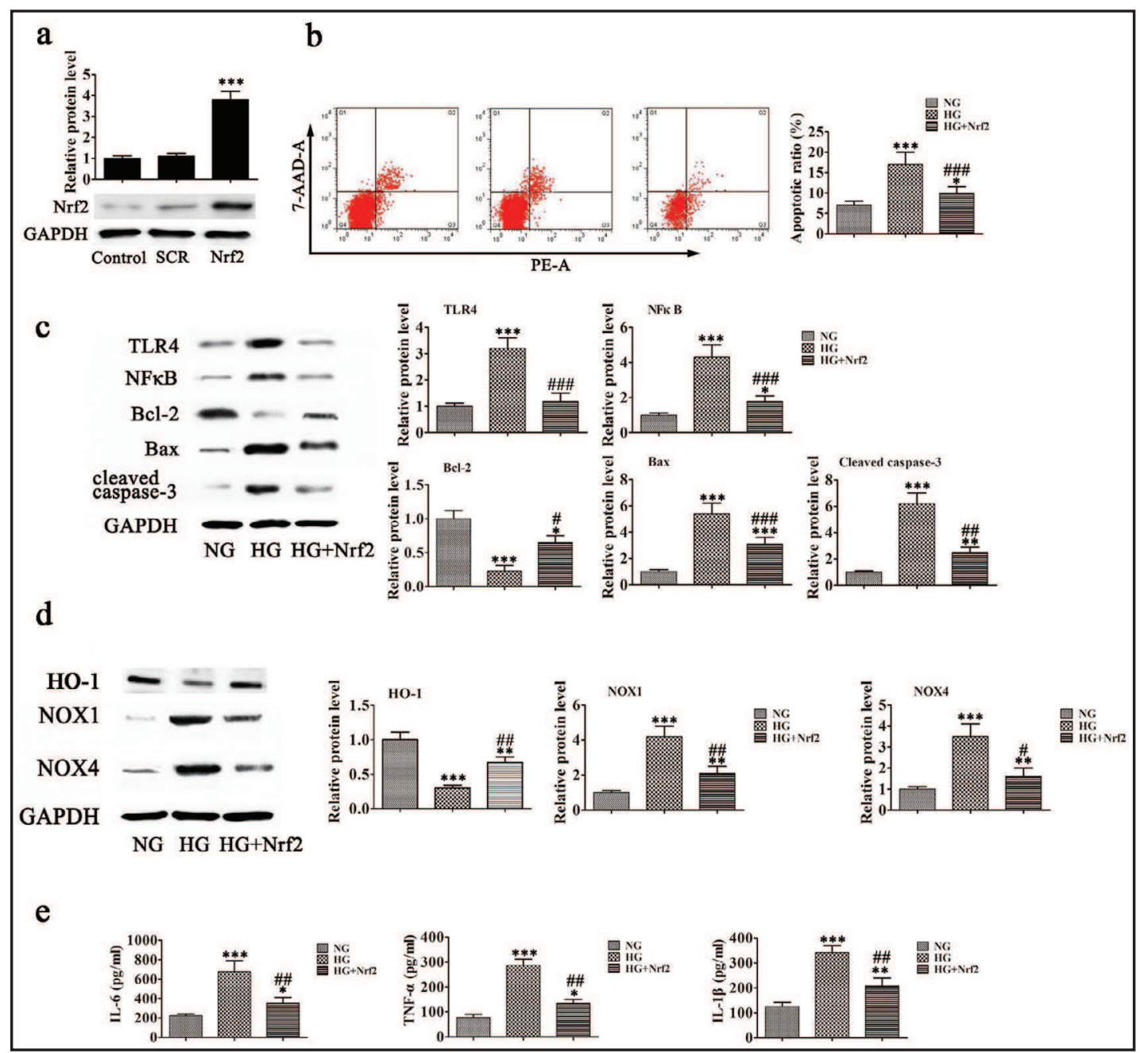

Fig. 3. The expression of Nrf2 promotes survival of Schwann cells (SCs) by inhibiting TLR4/NFkB-mediated ROS and inflammatory factors in high glucose (HG) conditions. (a) The relative protein and RNA levels of Nrf2 were measured by western blot and RT-qPCR, respectively. The results show that the expression of Nrf2 was upregulated after transfection with the Nrf2 vector. Data were represented as mean \pm SD ( $n=$ 3). ${ }^{* * *} \mathrm{P}<0.001$ vs control. SCR, transfected with scrambled vector. (b) Apoptosis were assessed using flow cytometry with annexin $\mathrm{v}$-PE/7-AAD staining. The relative apoptotic ratio was analyzed with at least five repeats. Data were represented as mean $\pm \mathrm{SD}(\mathrm{n}=5)$. ${ }^{*} \mathrm{P}<0.05,{ }^{* * *} \mathrm{P}<0.001$ vs NG group. ${ }^{\# \# \#} \mathrm{P}<0.001$ vs HG group. (c) TLR4/NFKB signaling and apoptosis-related proteins were measured by western blot. Data are

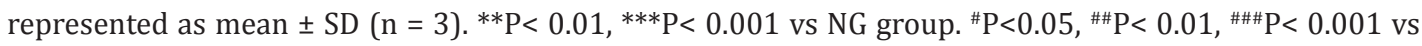
HG group. (d) The expression of ROS-related proteins HO-1, NOX1, and NOX4 were measured by western blotting. The relative protein level was analyzed and data were represented as mean $\pm \mathrm{SD}(\mathrm{n}=3) .{ }^{* * *} \mathrm{P}<0.001$ vs NG group. ${ }^{\mathrm{P}}<0.05,{ }^{\# \#} \mathrm{P}<0.01$ vs HG group. (e) Inflammatory cytokine levels of IL-1 $\beta$, IL- 6 and TNF- $\alpha$ were measured with ELISA. The relative protein levels were analyzed and data are represented as mean \pm SD (n = 3). ${ }^{*} \mathrm{P}<0.05,{ }^{* *} \mathrm{P}<0.01,{ }^{* * *} \mathrm{P}<0.001$ vs NG group. ${ }^{\# \#} \mathrm{P}<0.01$ vs HG group.

HG, $P<0.01$ vs NG) are reduced. We also measured the levels of inflammatory cytokines IL$1 \beta$, IL- 6 , and TNF- $\alpha$ with ELISA. The relative protein levels and data are represented as mean \pm SD in Fig. 3e. Although levels of IL-1 $\beta$, IL-6, and TNF- $\alpha$ were still significantly higher than in SCs cultured in NG they were found to be significantly reduced when Nrf2 is overexpressed $(P<0.01 \mathrm{vs} \mathrm{HG})$. The combination of these results supports the theory that overexpression of Nrf2 promotes the survival of SCs by inhibiting TLR4/NFKB-mediated ROS and inflammatory factors in hyperglycemic conditions. 
Fig. 4. The overexpression of Nrf2 promotes endothelial progenitor cell (EPC) migration and vasculogenic mimicry formation. (a) In order to determine the effect of Nrf2 expression in Schwann cells (SCs) on VEGF secretion and EPC surface VEGF receptor 2 (VEGFR2) activation. The diagram describes the cell co-culture system in which EPCs were cultured in the lower chamber and SCs were cultured in the upper chamber of a 12well insert. After $48 \mathrm{~h}$ of culture in HG pretreated with or without GKT137831 (NOX1/4 inhibitor) or CBO-P11 (VEGF inhibitor), the protein expression level of VEGF and phosphorylation of VEGFR2 on the surface of EPCs were determined by western blot. (b) VEGF secretion in the supernatant was determined by ELISA. Data are represented as the mean \pm SD ( $\mathrm{n}=5) .{ }^{* * *} \mathrm{P}<0.001$ vs $\mathrm{HG}$ group. (c) The results show that phosphorylation activation was increased with overexpression of Nrf2 or treated with a NOX1/4 inhibitor (GKT137831, $20 \mathrm{ng} / \mathrm{ml}$ ).
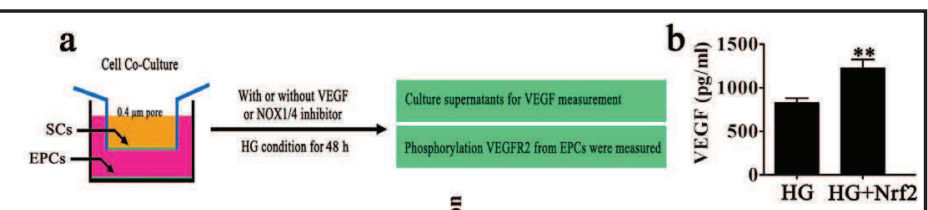

c

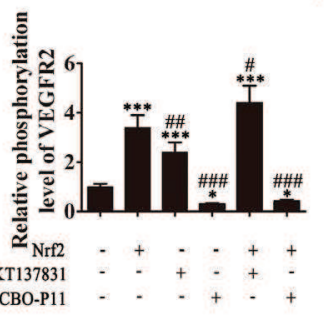

d

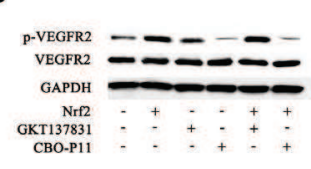

HG $\mathrm{HG}+\mathrm{Nrf2}$
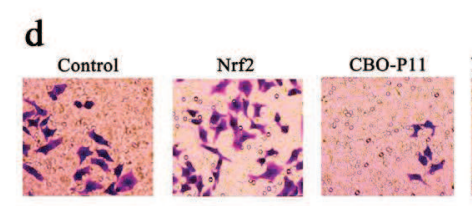

물
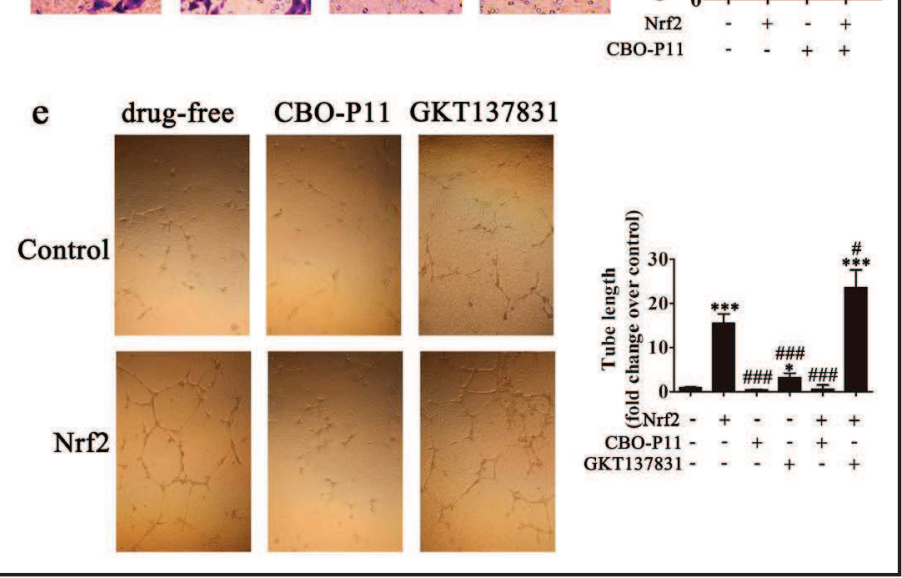
This means that the expression of

Nrf2 promotes VEGFR2 activation by decreasing ROS. Data were represented as mean $\pm S D(n=5)$. ${ }^{P}<0.05$, ${ }^{* * *} \mathrm{P}<0.001$ vs control group. ${ }^{\#} \mathrm{P}<0.05$, ${ }^{\# \#} \mathrm{P}<0.01$, ${ }^{\# \# \#} \mathrm{P}<0.001$ vs Nrf2 group. (d) The migration of EPC cells was induced by HG culture medium from SC, SCs overexpressing Nrf2 or Nrf2 overexpressing SCs + CBO-P11 $(10 \mu \mathrm{M})$. EPCs adherent to the underside of the transwells were visualized by microscopy and cell migration to the underside of the chamber was quantified by cell counting. Data are represented as the mean $\pm \operatorname{SD}(\mathrm{n}=$

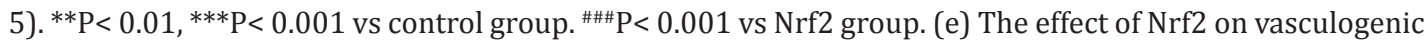
mimicry formation of EPCs was measured. The results show that the overexpression of Nrf2 promotes the vascularization of EPCs. ${ }^{*} \mathrm{P}<0.05,{ }^{* * *} \mathrm{P}<0.001$ vs control group. ${ }^{\#} \mathrm{P}<0.05$, ${ }^{\# \#} \mathrm{P}<0.001$ vs Nrf2 group.

The Overexpression of Nrf2 Promotes Endothelial Progenitor Cell Migration and Vasculogenic Mimicry Formation

In order to determine the effect of Nrf2 expression in SCs on VEGF secretion and EPC surface VEGFR2 activation, EPCs were co-cultured with SC with or without GKT137831 (NOX1/4 inhibitor) or CBO-P11 (VEGF inhibitor) as shown in Fig. 4a. The protein expression levels of VEGF and phosphorylation of VEGFR2 on the surface of EPCs were determined by western blot (Fig. 4b). VEGF secretion levels in the supernatant were measured by ELISA and found to be significantly higher in SCs overexpressing Nrf2 $(P<0.01)$. The results also show that phosphorylation of VEGFR2 was increased with overexpression of Nrf2 or in the presence of a NOX1/4 inhibitor (GKT137831). This suggests that overexpression of Nrf2 promotes VEGFR2 activation by decreasing ROS (Fig. 4c). EPCs adherent to the underside of the transwells were visualized by microscopy and cell migration was quantified by counting cells (Fig. 4d). The migration of EPCs was induced in HG by Nrf2 overexpression in SCs $(P<0.001)$ 


\section{Cellular Physiology Cell Physiol Biochem 2018;46:1879-1894 \begin{tabular}{ll|l|l} 
DOI: 10.1159/000489373 & (C) 2018 The Author(s). Published by S. Karger AG, Basel
\end{tabular}

Fig. 5. Transplantation with Schwann cells (SCs) overexpressing Nrf2 promotes the restoration of crushed sciatic nerves through increased vascularity of sciatic vasa nervorum in DN rats. Transplantation with SCs overexpressing Nrf2 increased both vascularity and nerve density in crushed sciatic nerves. Representative fluorescence images of cross-sections of sciatic nerves with NeuN

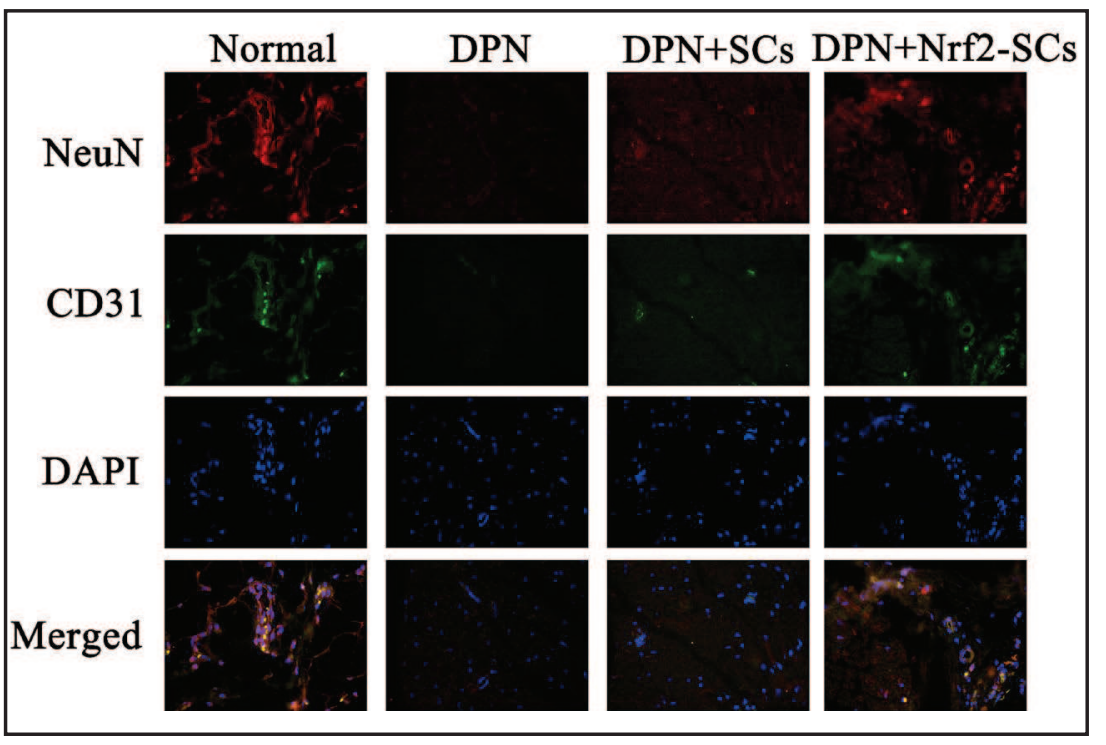
staining (red) and CD31 staining (Green) for vascularity. Magnification (400×). Scale bar, $50 \mu \mathrm{m}$.FIG. 6: The higher survival ratio of Schwann cells (SCs) overexpressing Nrf2 promotes the restoration of sciatic nerve conduction velocity in DPN rats with nerve injury. Two weeks after SC transplantation and 8 weeks of treatment with streptozotocin (55 mg/kg). Motor (a) and sensory (b) nerve conduction velocities (MNCV and SNCV) of the sciatic nerves were measured. $\mathrm{n}=6$. Data represent means $\pm \mathrm{SEM}$. ${ }^{* *} \mathrm{P}<0.01,{ }^{* * *} \mathrm{P}<0.001$ vs normal group.

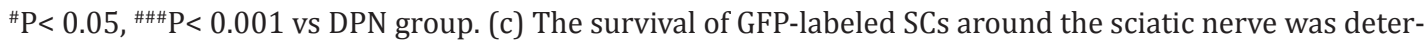
mined with a fluorescence microscope. (d) TEM of transverse sections of the regenerated nerves at 4 weeks post-neurography.

and inhibited in the presence of a VEGF inhibitor $(P<0.001$ vs Nrf2). The effect of Nrf2 overexpression on the vasculogenic mimicry formation of EPCs was measured in the presence of the NOX1/4 inhibitor GKT137831 and found to be significantly increased $(P<0.05)$ compared to overexpression without GKT137831 (Fig. 4e). Overall the results show that the overexpression of Nrf2 promotes the vascularization of EPCs.

Transplantation of Schwann Cells With Nrf2 Overexpressed Restores Crushed Sciatic Nerves Through the Increased Vascularity of the Vasa Nervorum

Transplantation with SCs overexpressing Nrf2 restored crushed sciatic nerves through increasing the vascularity of sciatic vasa nervorum in DN rats. Table 2 compares the quantity of nerve fibers, axon diameter of myelinated nerve fibers and myelin sheath thickness in control and rats transplanted with SCs and SCs overexpressing Nrf2 4 weeks postoperatively. Transplantation with SCs and SCs overexpressing Nrf2 increased both vascularity and nerve density in crushed sciatic nerves compared to the control with levels approaching close to normal for axon diameter of myelinated nerve fibers and myelin sheath thickness. 


\section{Cellular Physiology \\ Cell Physiol Biochem 2018;46:1879-1894 \\ \begin{tabular}{ll|l} 
and Biochemistry & Dublished online: 10.1159y 02, 2018 & $\begin{array}{l}\text { @ 2018 The Author(s). Published by S. Karger AG, Basel } \\
\text { www.karger.com/cpb }\end{array}$ \\
\cline { 2 - 4 }
\end{tabular}}

Tang et al.: Nrf2 Overexpression in Schwann Cells

Fig. 6. The higher survival ratio of Schwann cells (SCs) overexpressing Nrf2 promotes the restoration of sciatic nerve conduction velocity in DPN rats with nerve injury. Two weeks after SC transplantation and 8 weeks of treatment with streptozotocin (55 mg/kg). Motor (a) and sensory (b) nerve conduction velocities (MNCV and SNCV) of the sciatic nerves were measured. $n=6$. Data represent means \pm SEM. ${ }^{* *} \mathrm{P}<0.01,{ }^{* * *} \mathrm{P}<0.001$ vs normal group. ${ }^{\#} \mathrm{P}<0.05$, \#\#\# $\mathrm{P}<$ 0.001 vs DPN group. (c) The survival of GFP-labeled SCs around the sciatic nerve was determined with a fluorescence microscope. (d) TEM of transverse sections of the regenerated nerves at 4 weeks post-neurography.

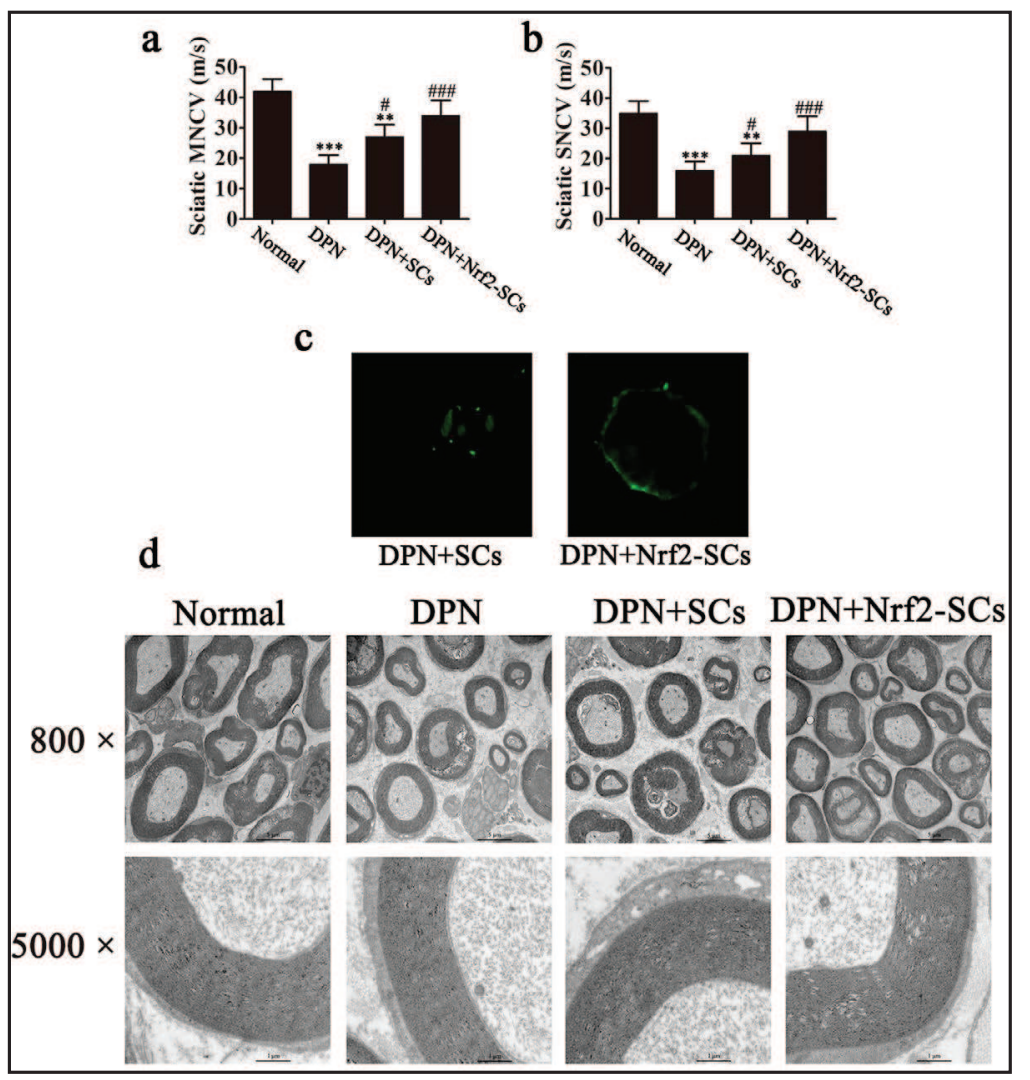

Representative fluorescence images of cross-sections of sciatic nerves are shown in Fig. 5. Two weeks after SC transplantation in rats induced for 8 weeks with STZ, MNCV and SNCV of the sciatic nerves were measured and found to improve significantly compared to the control group for both SCs $(P<0.05,0.05$, respectively) and SCs overexpressing Nrf2 $(P<0.001,0.001$, respectively) (Fig. 6a, b). There was no significant difference between sham injury operated rats and the normal group, therefore, only the control group data is shown. The survival of GFP-labeled SCs around the sciatic nerve was determined by fluorescence microscopy and indicated that there is an increased survival of SCs overexpressing Nrf2 (Fig. 6c). TEM of transverse sections of the regenerated nerves at 4 weeks post-neurography are shown in Fig. $6 \mathrm{~d}$. These results indicate that the higher survival ratio of SCs with overexpression of Nrf2 restored SNCV in nerve injury DPN rats and increased vascularity of the vasa nervorum.

\section{Discussion}

As Nrf2 has been implicated in promoting remyelination after peripheral nerve injury we investigated the possible role it may play in SC-mediated functional recovery after sciatic nerve injury. First, we investigated differences in inflammatory factors and VEGF expression between patients with and without diabetes-associated peripheral neuropathy. We then studied the effect of hyperglycemia in the presence and absence of Nrf2 on SC survival at the cellular level. Lastly, the therapeutic efficacy of Nrf2 overexpressed in SCs on repairing peripheral nerve injury was assessed in an animal model through targeted muscular injection.

In accordance with recent studies [8, 18-20], through measuring plasma levels of VEGF, IL-1 $\beta$, IL-6, TNF- $\alpha$, and TLR 4 we found that inflammatory factors and VEGF expression were higher in patients with DPN than in DN patients. These findings are in agreement with the 


\section{Cellular Physiology Cell Physiol Biochem 2018;46:1879-1894

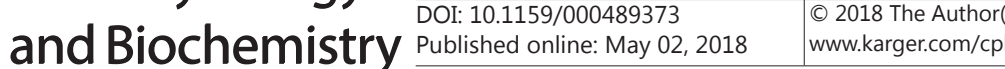

Tang et al.: Nrf2 Overexpression in Schwann Cells

theory that DPN may be associated with inflammation and endothelial dysfunction [21]. In patients without diabetes, hemoglobin A1c levels would be below 6.5\%. In patients with diabetes, a good to fair measurement would be 7.5-9.5\% even with treatment [22]. The measurements of the patients in our study were within that level but were still not within the normal range, therefore, other biochemical tests would reflect this. VEGF has been associated with DPN for some time but its exact role is unclear. Its expression was found to increase in the sciatic nerve and dorsal root ganglia of STZ-induced diabetic rats [23]. Schratzberger et al. partly reversed the development of reduced nerve conduction velocities and sensory nerve action potentials with a VEGF gene transfer in a rabbit ischemic peripheral neuropathy model and prevented the hypoxia-induced apoptosis of SCs in vitro [24]. However, in clinical trials, no great improvement was reported in nerve conduction velocities and despite the initial promise of gene therapy, there is still currently no treatment available that can effectively repair the damage induced by DPN [25-27]. Several traditional natural medicines have been found to relieve the symptoms of DPN through antioxidant properties and by inhibiting the apoptotic nature of SCs in hyperglycemic conditions $[28,29]$. For instance, Radix aconite lateralis preparata, a traditional Chinese medicine that has long been used to treat diabetes and paralysis, is thought to inhibit the apoptotic nature of SCs in hyperglycemic conditions through mitigated glucose-induced mitochondrial dysfunction [28]. Similarly, Yang et al. found by measuring MDA, SOD, and GSH-Px in the sciatic nerve tissue of STZ-induced DPN rats that Tang Bi Kang, another traditional Chinese medicine, could treat DPN through antioxidative and anti-inflammatory responses [29].

TAK-242 is a small-molecule inhibitor that binds selectively to TLR 4 and interferes with interactions between TLR4 and its adaptor molecules [30]. We cultured SCs in the presence of TAK-242 and found that peroxide and superoxide anion levels are higher in hyperglycemic conditions but the addition of a TLR4 inhibitor along with the subsequent inhibition of the TLR4/NFKB pathway was able to reduce these levels. We also investigated mRNA and protein levels of NOX1 and NOX4 in RSC96 cells. The biological function of NOX enzymes is to generate ROS during the process of innate immunity, signal transduction and modification of the extracellular matrix, and they have been identified as major contributors to oxidative damage in cells [31]. We found that NOX1 and NOX2 levels were higher in cells cultured in HG compared to NG and the addition of TAK-242 was effective in reducing these levels. Similarly, inflammatory cytokine levels of IL-1 $\beta$, IL- 6 , and TNF- $\alpha$ for both glucose concentrations were measured in the presence and absence of TAK-242 and the significantly higher levels found in SCs cultured with HG were reduced by the addition of the TLR4 inhibitor. Furthermore, we found that high ROS and inflammatory factor levels could affect the survival of SCs cultured in HG and this induced apoptosis could be partially prevented by TAK-242. The combination of these results suggests that HG can induce ROS and inflammatory factor levels in SCs through the activation of the TLR4/NFKB pathway and this could be controlled, to a certain extent, by inhibiting the pathway. Interestingly, in a similar study examining the role of oxidative stress in DPN, it has been proposed that the activation of an antioxidant response in dorsal root ganglion neurons may prevent glucose-induced injury [32].

Inflammation appears to play an important role in DPN. Inflammatory factors such as CRP and TNF- $\alpha$ are present in the blood of patients with type 1 and type 2 diabetes and correlate with the incidence of DPN [33]. Production of initiating inflammatory mediators, such as TNF- $\alpha$, TGF- $\beta$, and NF- $\kappa B$, results from several glucose-induced pathways and would be particularly predominate in glycemic conditions. The cytokines which are induced by the TLR4/NFKB pathway in SCs, endothelial cells, and neurons lead to the absorption of macrophages in the nerves. Macrophage recruitment promotes oxidative damage and myelin breakdown which eventually interfere with the regeneration of nerves [34, 35].

To further investigate the impact of the TLR4/NFKB pathway on the survival of SCs in hyperglycemic conditions, we overexpressed Nrf2 in SCs. The Nrf2 transcription factor binds to antioxidant response elements to elicit the response of antioxidative and phase-2 detoxifying enzymes and related stress-response proteins against oxidative and electrophilic insults [36]. Nrf2 is thought to promote remyelination after peripheral nerve 


\section{Cellular Physiology Cell Physiol Biochem 2018;46:1879-1894 and Biochemistry Published online: May 02, $2018 \quad \begin{aligned} & \text { O 2018 The Author(s) } \\ & \text { www.karger.com/cph }\end{aligned}$ \\ Tang et al.: Nrf2 Overexpression in Schwann Cells}

injury [16, 37-39]. Our experiments showed that overexpression of Nrf2 was able to prevent hyperglycemia-induced apoptosis by inhibiting the activity and expression of the TLR4/ NFKB signal pathway. Furthermore, the expression of Nrf2 in SCs also promotes angiogenesis of EPCs with co-culture through secretion of VEGF. The results show that phosphorylation activation was increased with overexpression of Nrf2 or when treated with the NOX1/4 inhibitor GKT137831. We found that the expression of Nrf2 promoted VEGFR2 activation by decreasing the levels of ROS. Venous hypertension has also been found to significantly increase the expression of Nrf2 and VEGF whereas Nrf2 knockdown inhibits the upregulation of VEGF [40].

Recently, Kim et al. tested the EPC mobilization effect of vascular VEGF and AMD3100 in an STZ-induced DN mouse model and found that AMD3100 was effective in mobilizing EPC although VEGF had no effect [9]. They administered AMD3100 systemically to stimulate EPC mobilization and injected stromal-cell-derived factor (SDF)-1 $\alpha$ locally to enhance its migration. Decreased local expression of SDF- $1 \alpha$ in DN patients can cause defective EPC migration [41]. The combined AMD3100 and SDF-1 $\alpha$ therapy in DN mice increased local expression levels of vasculogenesis-associated factors and regenerated endothelial cells in the sciatic nerve, restoring the sciatic vasa nervorum and improving the conduction velocity of the sciatic nerve [9]. We tested the effectiveness of SCs expressing Nrf2 in a DPN-induced rat model. Our animal experiments showed that nerve conduction velocity and myelin sheath thickness were restored with the transplantation of SCs expressing Nrf2. Similarly, immunofluorescence suggests that the survival of SCs and the density of sciatic vasa nervorum were increased with overexpression of Nrf2.

\section{Conclusion}

Hyperglycemic conditions in DN patients may promote the presence of inflammatory factors and elevated VEGF expression that are associated with DPN by activating the TLR4/ NFKB pathway. SCs cultured in HG have increased ROS and inflammatory factor levels. The activation of the TLR4/NFKB pathway interferes with SC survival and the ability to protect nerve cells from damage caused by oxidative stress and other factors. The overexpression of Nrf2 in SCs inhibits the TLR4/NFKB pathway and promotes SC survival. The high survival ratio of SCs in a DPN rat model indicates that overexpression of $\mathrm{Nrf} 2$ restores nerve injury.

\section{Acknowledgements}

This study was supported by the National Natural Science Foundation of China (Grant no. 81300672) and Shanghai Science and Technology Development Funds (Grant no. 14QB1403000)

WT, YS, and ZL designed and executed experiments, analyzed the data, and wrote the manuscript. XC designed the experiments and wrote the manuscript. HL designed, executed, and analyzed high content experiments. QL and JZ wrote the high throughput part of the manuscript.

\section{Disclosure Statement}

The authors declare that there are no conflicts of interest associated with this manuscript. 


\section{Cellular Physiology Cell Physiol Biochem 2018;46:1879-1894 \begin{tabular}{l|l} 
and Biochemistry Published online: May 02, 2018 & $\begin{array}{l}\text { ( ) 2018 The Author(s). Published by S. Karger AG, Basel } \\
\text { www.karger.com/cpb }\end{array}$ \\
\hline
\end{tabular}}

Tang et al.: Nrf2 Overexpression in Schwann Cells

\section{References}

1 Callaghan BC, Cheng HT, Stables CL, Smith AL, Feldman EL: Diabetic neuropathy: clinical manifestations and current treatments. Lancet Neurol 2012;11:521-534.

-2 Pop-Busui R, Lu J, Lopes N, Jones TL: Prevalence of diabetic peripheral neuropathy and relation to glycemic control therapies at baseline in the BARI 2D cohort. J Peripher Nerv Syst 2009;14:1-13.

-3 Sugimoto K, Murakawa Y, Sima AA: Diabetic neuropathy--a continuing enigma. Diabetes Metab Res Rev 2000;16:408-433.

4 Vinik AI, Park TS, Stansberry KB, Pittenger GL: Diabetic neuropathies. Diabetologia 2000;43:957-973.

5 Low PA, Lagerlund TD, McManis PG: Nerve blood flow and oxygen delivery in normal, diabetic, and ischemic neuropathy. Int Rev Neurobiol 1989;31:355-438.

6 Boulton AJ: Diabetic neuropathy: classification, measurement and treatment. Curr Opin Endocrinol Diabetes Obes 2007;14:141-145.

7 West XZ, Malinin NL, Merkulova AA, Tischenko M, Kerr BA, Borden EC, Podrez EA, Salomon RG, Byzova TV: Oxidative stress induces angiogenesis by activating TLR2 with novel endogenous ligands. Nature 2010;467:972-976.

8 Zhu T, Meng Q Ji J, Lou X, Zhang L: Toll-like receptor 4 and tumor necrosis factor-alpha as diagnostic biomarkers for diabetic peripheral neuropathy. Neurosci Lett 2015;585:28-32.

-9 Kim BJ, Lee JK, Schuchman EH, Jin HK, Bae JS: Synergistic vasculogenic effects of AMD3100 and stromalcell-derived factor-1alpha in vasa nervorum of the sciatic nerve of mice with diabetic peripheral neuropathy. Cell Tissue Res 2013;354:395-407.

10 Lehmann HC, Hoke A: Schwann cells as a therapeutic target for peripheral neuropathies. CNS Neurol Disord Drug Targets 2010;9:801-806.

-11 Steed MB, Mukhatyar V, Valmikinathan C, Bellamkonda RV: Advances in bioengineered conduits for peripheral nerve regeneration. Atlas Oral Maxillofac Surg Clin North Am 2011;19:119-130.

12 Wei Y, Gong K, Zheng Z, Liu L, Wang A, Zhang L, Ao Q, Gong Y, Zhang X: Schwann-like cell differentiation of rat adipose-derived stem cells by indirect co-culture with Schwann cells in vitro. Cell Prolif 2010;43:606616.

13 Dai LG, Huang GS, Hsu SH: Sciatic nerve regeneration by cocultured Schwann cells and stem cells on microporous nerve conduits. Cell Transplant 2013;22:2029-2039.

14 Li Q Ping P, Jiang H, Liu K: Nerve conduit filled with GDNF gene-modified Schwann cells enhances regeneration of the peripheral nerve. Microsurgery 2006;26:116-121.

15 Santosa KB, Jesuraj NJ, Viader A, MacEwan M, Newton P, Hunter DA, Mackinnon SE, Johnson PJ: Nerve allografts supplemented with Schwann cells overexpressing glial-cell-line-derived neurotrophic factor. Muscle Nerve 2013;47:213-223.

16 Xiong W, MacColl Garfinkel AE, Li Y, Benowitz LI, Cepko CL: NRF2 promotes neuronal survival in neurodegeneration and acute nerve damage. J Clin Invest 2015;125:1433-1445.

17 Negi G, Kumar A, Sharma SS: Nrf2 and NF-kappaB modulation by sulforaphane counteracts multiple manifestations of diabetic neuropathy in rats and high glucose-induced changes. Curr Neurovasc Res 2011;8:294-304.

18 Motawi TK, Rizk SM, Ibrahim IA, El-Emady YF: Alterations in circulating angiogenic and anti-angiogenic factors in type 2 diabetic patients with neuropathy. Cell Biochem Funct 2014;32:155-163.

-19 Hanefeld M, Appelt D, Engelmann K, Sandner D, Bornstein SR, Ganz X, Henkel E, Haase R, Birkenfeld AL: Serum and Plasma Levels of Vascular Endothelial Growth Factors in Relation to Quality of Glucose Control, Biomarkers of Inflammation, and Diabetic Nephropathy. Horm Metab Res 2016;48:620.

20 Li X, Wu TT, Chen J, Qiu W: Elevated expression levels of serum insulin-like growth factor-1, tumor necrosis factor-alpha and vascular endothelial growth factor 165 might exacerbate type 2 diabetic nephropathy. J Diabetes Investig 2016

21 Doupis J, Lyons TE, Wu S, Gnardellis C, Dinh T, Veves A: Microvascular reactivity and inflammatory cytokines in painful and painless peripheral diabetic neuropathy. J Clin Endocrinol Metab 2009;94:21572163.

-22 Kahlon AS, Pathak R: Patterns of glycemic control using glycosylated hemoglobin in diabetics. J Pharm Bioallied Sci. 2011;3:324-328. 


\section{Cellular Physiology Cell Physiol Biochem 2018;46:1879-1894 \begin{tabular}{l|l} 
and Biochemistry Published online: May 02, 2018 & $\begin{array}{l}\text { ( ) 2018 The Author(s). Published by S. Karger AG, Basel } \\
\text { www.karger.com/cpb }\end{array}$ \\
\hline
\end{tabular}}

Tang et al.: Nrf2 Overexpression in Schwann Cells

23 Samii A, Unger J, Lange W: Vascular endothelial growth factor expression in peripheral nerves and dorsal root ganglia in diabetic neuropathy in rats. Neurosci Lett 1999;262:159-162.

-24 Schratzberger P, Schratzberger G, Silver M, Curry C, Kearney M, Magner M, Alroy J, Adelman LS, Weinberg DH, Ropper AH, Isner JM: Favorable effect of VEGF gene transfer on ischemic peripheral neuropathy. Nat Med 2000;6:405-413.

-25 Ropper AH, Gorson KC, Gooch CL, Weinberg DH, Pieczek A, Ware JH, Kershen J, Rogers A, Simovic D, Schratzberger P, Kirchmair R, Losordo D: Vascular endothelial growth factor gene transfer for diabetic polyneuropathy: a randomized, double-blinded trial. Ann Neurol 2009;65:386-393.

-26 Kim H, Kim JJ, Yoon YS: Emerging therapy for diabetic neuropathy: cell therapy targeting vessels and nerves. Endocr Metab Immune Disord Drug Targets 2012;12:168-178.

27 Muona K, Makinen K, Hedman M, Manninen H, Yla-Herttuala S: 10-year safety follow-up in patients with local VEGF gene transfer to ischemic lower limb. Gene Ther 2012;19:392-395.

-28 Han J, Tan P, Li Z, Wu Y, Li C, Wang Y, Wang B, Zhao S, Liu Y: Fuzi attenuates diabetic neuropathy in rats and protects Schwann cells from apoptosis induced by high glucose. PLoS One 2014;9:e86539.

29 Yang XW, Liu FQ Guo JJ, Yao WJ, Li QQ Liu TH, Xu LP: Antioxidation and anti-inflammatory activity of Tang Bi Kang in rats with diabetic peripheral neuropathy. BMC Complement Altern Med 2015;15:66.

-30 Matsunaga N, Tsuchimori N, Matsumoto T, Ii M: TAK-242 (resatorvid), a small-molecule inhibitor of Tolllike receptor (TLR) 4 signaling, binds selectively to TLR4 and interferes with interactions between TLR4 and its adaptor molecules. Mol Pharmacol 2011;79:34-41.

-31 Bedard K, Krause KH: The NOX family of ROS-generating NADPH oxidases: physiology and pathophysiology. Physiol Rev 2007;87:245-313.

32 Vincent AM, Kato K, McLean LL, Soules ME, Feldman EL: Sensory neurons and Schwann cells respond to oxidative stress by increasing antioxidant defense mechanisms. Antioxid Redox Signal 2009;11:425-438.

-33 Hosseini A, Abdollahi M: Diabetic neuropathy and oxidative stress: therapeutic perspectives. Oxid Med Cell Longev 2013;2013:168039.

34 Edwards JL, Vincent AM, Cheng HT, Feldman EL: Diabetic neuropathy: mechanisms to management. Pharmacol Ther 2008;120:1-34.

-35 Yagihashi S, Mizukami H, Sugimoto K: Mechanism of diabetic neuropathy: Where are we now and where to go? J Diabetes Investig 2011;2:18-32.

-36 Kim J, Cha YN, Surh YJ: A protective role of nuclear factor-erythroid 2-related factor-2 (Nrf2) in inflammatory disorders. Mutat Res 2010;690:12-23.

-37 Zhang M, An C, Gao Y, Leak RK, Chen J, Zhang F: Emerging roles of Nrf2 and phase II antioxidant enzymes in neuroprotection. Prog Neurobiol 2013;100:30-47.

-38 Zhang L, Johnson D, Johnson JA: Deletion of Nrf2 impairs functional recovery, reduces clearance of myelin debris and decreases axonal remyelination after peripheral nerve injury. Neurobiol Dis 2013;54:329-338.

-39 Lee H, Lee M, Lee Y, Choi S, Yang J: Chondrocyte-derived extracellular matrix suppresses pathogenesis of human pterygium epithelial cells by blocking the NF-kappaB signaling pathways. Mol Vis 2016;22:14901502.

40 Li L, Pan H, Wang H, Li X, Bu X, Wang Q Gao Y, Wen G, Zhou Y, Cong Z, Yang Y, Tang C, Liu Z: Interplay between VEGF and Nrf2 regulates angiogenesis due to intracranial venous hypertension. Sci Rep 2016;6:37338.

-41 Fadini GP, Sartore S, Agostini C, Avogaro A: Significance of endothelial progenitor cells in subjects with diabetes. Diabetes Care 2007;30:1305-1313. 